\title{
NR4A Gene Expression Is Dynamically Regulated in the Ventral Tegmental Area Dopamine Neurons and Is Related to Expression of Dopamine Neurotransmission Genes
}

\author{
Jeffrey B. Eells • Josiah Wilcots • Scott Sisk • \\ Shirley X. Guo-Ross
}

Received: 1 July 2011 / Accepted: 24 August 2011 / Published online: 20 September 2011

(C) The Author(s) 2011. This article is published with open access at Springerlink.com

\begin{abstract}
The NR4A transcription factors NR4A1, NR4A2, and NR4A3 (also known as Nur77, Nurr1, and Nor1, respectively) share similar DNA-binding properties and have been implicated in regulation of dopamine neurotransmission genes. Our current hypothesis is that NR4A gene expression is regulated by dopamine neuron activity and that induction of NR4A genes will increase expression of dopamine neurotransmission genes. Eticlopride and $\gamma$-butyrolactone (GBL) were used in wild-type $(+/+)$ and Nurr1-null heterozygous $(+/-)$ mice to determine the mechanism(s) regulating Nur77 and Nurrl expression. Laser capture microdissection and realtime PCR was used to measure Nurr1 and Nur77 mRNA levels in the ventral tegmental area (VTA). Nur77 expression was significantly elevated $1 \mathrm{~h}$ after both GBL (twofold) and eticlopride (fourfold). In contrast, GBL significantly decreased Nurr1 expression in both genotypes, while eticlopride significantly increased Nurr 1 expression only in the $+/+$ mice. In a separate group of mice, haloperidol injection significantly elevated Nur77 and Nor1, but not Nurr1 mRNA in the VTA within $1 \mathrm{~h}$ and significantly increased tyrosine hydroxylase (TH) and dopamine transporter (DAT) mRNA expression by $4 \mathrm{~h}$. These data demonstrate that the NR4A genes are dynamically regulated in dopamine neurons with maintenance of Nurr1 expression requiring dopamine neuron activity while both attenuation of dopamine autoreceptors activation and dopamine neuronal activity combining to induce Nur77 expression. Additionally, these data suggest that induction of NR4A genes could regulate TH and DAT expression and ultimately regulate dopamine neurotransmission.
\end{abstract}

J. B. Eells $(\triangle) \cdot J$. Wilcots $\cdot$ S. Sisk $\cdot$ S. X. Guo-Ross

Department of Basic Sciences, College of Veterinary Medicine,

Mississippi State University,

Mississippi State, MS 39762, USA

e-mail: eells@cvm.msstate.edu
Keywords $\mathrm{Nr} 4 \mathrm{a} \cdot \mathrm{Nurr} 1 \cdot \mathrm{Nur} 77 \cdot$ Nor1 $\cdot$ Tyrosine hydroxylase $\cdot$ Dopamine transporter . Laser capture microdissection

\section{Introduction}

The NR4A genes consist of a group of transcription factors that includes Nur77 (NR4A1), Nurr1 (NR4A2), and Nor1 (NR4A3). The NR4A proteins share a very similar DNAbinding domain and DNA response element binding properties. All three of these proteins can bind as monomers to the octomeric sequence termed the Nur77 binding response element (NBRE) or as hetero or homodimers on the Nur77 response element, an inverted repeat of the NBRE separated by six nucleotides, and induce reporter gene expression in vitro (Wilson et al. 1991; Paulsen et al. 1995; Murphy et al. 1996; Philips et al. 1997; Maira et al. 1999; Maira et al. 2003). Although differences in DNAbinding affinities and heterodimerization properties have been reported, the similarities in DNA-binding properties suggest that these proteins, when expressed together, could have similar effects on target gene regulation. Additionally, the NR4A transcription factors can serve as heterodimer pairs with other transcription factors such as the retinoid $\mathrm{X}$ receptor and COUP-TF (Perlmann and Jansson 1995; Wu et al. 1997). The NR4A genes are also inducible transcription factors which have been shown to be induced rapidly in neurons, thus providing a mechanism of coupling changes in electrophysiology and/or neurotransmission with regulation of neuron gene expression (Hosford et al. 1995; Xing et al. 1997; Honkaniemi and Sharp 1999).

The mesolimbic dopamine neurons, which are located in the ventral tegmental area (VTA) and innervate the nucleus accumbens as well as limbic and cortical structures, have 
been implicated in a number of brain functions including regulating reward and discerning relevant stimuli (reviewed in Tzschentke 2001). Aberrant function of this pathway has been implicated in symptoms of schizophrenia, attention deficit-hyperactivity disorder, and addiction. The NR4A transcription factors have been shown to have important roles in regulating dopamine neurotransmission. Nurr1 is expressed in mesencephalic dopamine neurons during development and is necessary for differentiation of these neurons (Zetterström et al. 1997; Castillo et al. 1998; Saucedo-Cardenas et al. 1998). Additionally, Nurr1 is necessary for survival of these neurons and has been implicated in regulation of genes necessary for dopamine neurotransmission such as tyrosine hydroxylase (TH), GTP cyclohydrolase, dopamine transporter (DAT), and vesicular monoamine transporter (Iwawaki et al. 2000; Sacchetti et al. 2001; Hermanson et al. 2003; Jankovic et al. 2005; Eells et al. 2006; Gil et al. 2007; Kadkhodaei et al. 2009). Nurr1 function is particularly important for mesoaccumbens dopamine neurotransmission as reduced Nurrl expression, as found in Nurr1-null heterozygous mice, results in reduced dopamine levels and reduced dopamine synthesis in the nucleus accumbens (Eells et al. 2002; Eells et al. 2006). In contrast to Nurr1, Nur77 and Nor1 are typically expressed in targets of dopamine innervations such as the medium spiny neurons in the striatum and nucleus accumbens and can affect dopamine neurotransmission (Zetterström et al. 1996; Maheux et al. 2005; Gilbert et al. 2006). Although Nur77 and Nor1 expression is low, (undetectable with in situ hybridization) in mesencephalic dopamine neurons, expression of these genes can be induced by antipsychotic drugs which primarily are antagonist of the dopamine D2 receptor (Saucedo-Cardenas and Conneely 1996; Maheux et al. 2005). Due to the similar DNA-binding properties between the NR4A proteins and the function of Nurrl in mesoaccumbens dopamine neurons, expression of Nur77 and Nor1 in dopamine neurons could have important implications on dopamine neurotransmission.

Currently, the mechanism(s) responsible for regulating expression of the NR4A genes and the consequence(s) on dopamine neuron gene expression after induction of NR4A genes has not been investigated. The first part of the current study was designed to determine the mechanism(s) responsible for regulation of Nur77 and Nurr1 expression. The current experiments used the drug $\gamma$-butyrolactone (GBL), which blocks impulse flow of dopamine neurons, reducing dopamine release, and subsequent activation of the dopamine autoreceptor, to differentiate between dopamine neuron activity and release from activation of the dopamine autoreceptor. A systemic D2 receptor antagonist, however, will similarly reduce activation of the dopamine autoreceptor but also results in an increase in activity of the dopamine neurons with an increase in dopamine release (reviewed in Tzschentke 2001). Expression of Nur77 and Nurr1 mRNA was compared after treatment with the D2 receptor antagonist eticlopride and GBL. The second part of the study was designed to determine the effect of induction of NR4A genes by a dopamine D2 receptor antagonist (haloperidol) on dopamine neurotransmission gene expression. Nur77 and Nurr1 expression was elevated by eticlopride, while GBL significantly reduced Nurr1 expression but elevated Nur77 expression. Furthermore, antagonism of the D2 receptor, which significantly increased Nur77 and Nor1 expression at $1 \mathrm{~h}$, resulted in a significant increase in TH and DAT expression at $4 \mathrm{~h}$. These data suggest that both Nur77 and Nurr1 are dynamically regulated in the VTA and that these changes may have direct consequences on dopamine neurotransmission genes.

\section{Methods}

\section{Chemicals and Reagents}

Haloperidol, GBL, and eticlopride were purchased from Sigma with $99 \%$ purity. Acetic acid, $0.1 \mathrm{M}$, was used to dissolve haloperidol into solution, which was then further diluted with saline to reach a final concentration $0.1 \mathrm{mg} / \mathrm{ml}$.

\section{Animals}

Animals were housed at Mississippi State University in an AAALAC-accredited facility on 12-h light/dark cycle with food and water available ad libitum. Nurr1-null heterozygous mice used for the first part of this study were obtained from a colony bred at Mississippi State University originally produced in the laboratory of Dr. Vera Nikodem at the National Institute for Diabetes and Digestive and Kidney Diseases (Castillo et al. 1998). Mice were genotyped as previously described to distinguish $+/-$ and $+/+$ mice (Castillo et al. 1998). At 19-21 days of age, mice were weaned and housed in groups of three to five per cage. Ninety-day-old male HSD:ICR outbred mice were purchased from Harlan Bioproducts for Science for the second part of this study. All mice were housed in cages with steel grid lids and all cages were located in the same room. All procedures were performed in accordance with the National Institutes of Health Guide for the Care and Use of Laboratory Animals, and study protocols were approved by the Institutional Animal Care and Use Committee at Mississippi State University. All animals used in this project were housed in the AAALAC-accredited facilities of the College of Veterinary Medicine, Mississippi State University. The individual room temperatures were maintained between $18^{\circ} \mathrm{C}$ and $22^{\circ} \mathrm{C}$ with food and water ad 
libitum. Care of the mice was overseen by a laboratory animal veterinarian.

For the first experiment, adult Nurr1-heterozygous and wild-type littermate mice were divided into four groups of six mice in each genotype $(+/+$ and $+/-)$ and treatment (vehicle, GBL, and eticlopride). Each mouse received a single intraperitoneal injection of $0.9 \%$ saline, $1 \mathrm{mg} / \mathrm{kg}$ eticlopride, or $750 \mathrm{mg} / \mathrm{kg}$ GBL. For the second experiment, a total of 32 HSD:ICR outbred mice were divided into two groups consisting of vehicle or haloperidol treatment with 16 mice in each group. Haloperidol was administered via intraperitoneal injection at a dose of $1 \mathrm{mg} / \mathrm{kg}$. Saline acetic acid solution served as our vehicle treatment. Mice were then sacrificed 1 and $4 \mathrm{~h}$ after either vehicle or haloperidol injection, with eight mice in each treatment and time point. At the end of the experiments, mice were euthanized by $\mathrm{CO}_{2}$ asphyxiation. After asphyxiation, all mice were decapitated and the brain removed. A coronal cut was made in the brain at approximately $1 \mathrm{~mm}$ caudal to bregma, which separated the brain into two distinct regions (midbrain and forebrain). The brain tissue was frozen on dry ice and stored at $-80^{\circ} \mathrm{C}$.

\section{Tissue Dissection for RNA Isolation}

The brainstem of the HSD:ICR outbred mice were attached to a custom-made cold aluminum tissue slicer using TissueTek O.C.T. compound and sectioned into 400-600- $\mu \mathrm{m}$ frozen sections with a razor blade. Using an 18-gauge blunt needle, punches from the VTA were made for RNA isolation. To isolate the VTA in the Nurr1 mice, immunohistochemistry-guided, laser capture microdissection was used. In the Nurr1 transgenic mice, the brainstem was sectioned into $10-\mu \mathrm{m}$ section with a cryostat and alternate sections were collected onto silanized slides. For each mouse, one slide was processed for fluorescent tyrosine hydroxylase immunohistochemistry as previous described (Eells et al. 2001). Briefly the section was fixed with 4\% paraformaldehyde for $30 \mathrm{~min}$, washed in phosphate-buffered saline, incubated with tyrosine hydroxylase primary antibody (Chemicon) at a concentration of 1:2,000 for $2 \mathrm{~h}$, rinsed with phosphate-buffered saline then incubated in goat anti-rabbit IgG conjugated to AlexaFluor 488 (Invitrogen) for $2 \mathrm{~h}$. Sections were counter-stained with DAPI and coverslipped with Permount. For laser capture microdissection, another slide with adjacent sections from the immunostained slide, was fixed for $2 \mathrm{~min}$ in acetone at $4{ }^{\circ} \mathrm{C}$, air-dried, then dehydrated through a series of concentrations of RNase-free ethanol (75-80-95-100-100\%) then cleared with two successive incubations in xylene. Using the slide labeled for tyrosine hydroxylase immunohistochemistry as a guide (Fig. 1), the region of the sections with tyrosine hydroxylase immunoreactive neurons in the VTA
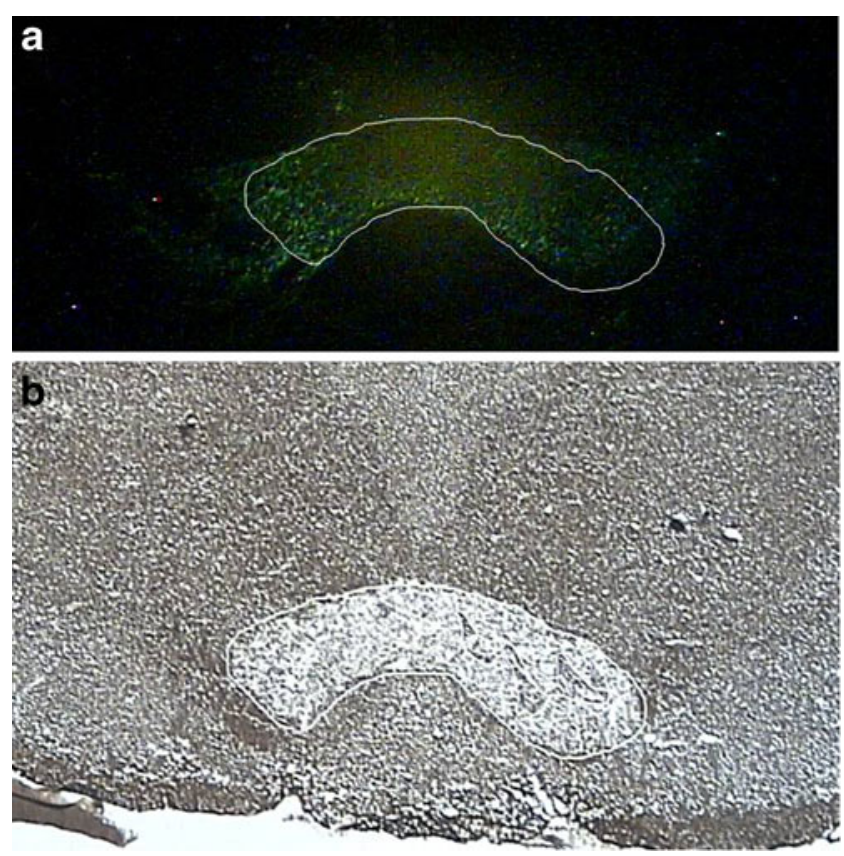

Fig. 1 Dopamine neurons in the ventral tegmental area are shown after tyrosine hydroxylase immunohistochemistry (a). This area was used to determine the distribution of dopamine neurons and used to dissect tissue from an adjacent section processed for laser capture microdissection (b)

was outlined and captured onto CapSure Macro LCM caps (Applied Biosystems).

\section{Tissue Dissection for Catecholamine Measurements}

The frozen forebrain tissue was mounted in a custom-made tissue slicer with O.C.T. compound (Sakura Finetek, Torrance, CA) and 600-800- $\mu \mathrm{m}$ frozen sections were cut and mounted on glass slides. Micropunches of the dorsal striatum were isolated using a blunt 20-gauge needle while micropunches of the nucleus accumbens were isolated with an 18-gauge blunt needle. Micropunches were used for determination of dopamine and metabolite levels using high-performance liquid chromatography and electrochemical detection.

\section{Catecholamine Measurements}

Tissue catecholamine levels were measured as previously described (Eells and Brown 2009). Tissues micropunches were homogenized in $100 \mu \mathrm{l}$ of $0.1 \mathrm{M}$ perchloric acid, cleared by two rounds of centrifugation at $10,000 \times g$ and the supernatant was injected into a high-pressure liquid chromatography system consisting of a Waters 2695 Separation module, a SupleCosil LC-18-DB column with the Waters 2465 electrochemical detector. The electrochemical detector was set at $5 \mathrm{nA}$ and an $\mathrm{Ec}=+0.67 \mathrm{~V}$ using a mobile phase of $100 \mathrm{mM}$ phosphate, $17.5 \%$ methanol, $25 \mathrm{mM}$ EDTA, and $1 \mathrm{mM}$ octyl sodium sulfate at $\mathrm{pH} 3.65$. 
These conditions provide good separation and detection of dopamine and its metabolite 3,4 dihydroxyphenylacetic acid (DOPAC). The quantity of each compound was determined based on the response of a known amount of standards. The BCA protein assay was performed on the remaining pellets to normalize based on amount of protein in each micropunch. Pellets were solubilized with $100 \mu$ of $0.5 \mathrm{M} \mathrm{NaOH}$ by incubating at $37^{\circ} \mathrm{C}$ for $1 \mathrm{~h}$. Distilled water was then added to the samples $(200 \mu$ l to nucleus accumbens samples) and incubated for an additional $30 \mathrm{~min}$. The samples were loaded into a 96-well plate and assayed using the ThermoMax microplate reader with Softmax pro software. Bovine serum albumin was used as the protein standard.

\section{RNA Isolation and Q-PCR}

RNA from micropunches of the VTA was isolated using Absolutely RNA Microprep Kit according to manufacturer's directions (Stratagene). After isolation of RNA, cDNA was made using the Qiagen omniscript reverse transcriptase kit using oligo $\mathrm{dT}$ and random hexamers. RNA from the VTA dissected using laser capture microdissection was isolated using the PicoPure RNA isolation kits (Molecular Devices). RNA was reverse transcribed using Superscript III with a combination of oligo dT and random hexamers according to manufactures instructions (Invitrogen). Lux primers were designed to measure Nur77, Nurr1, Nor1, TH, DOPA decarboxylase, DAT, dopamine D2 receptor, vesicular monoamine transporter 2, and the internal control gene $\beta$-actin (Table 1). To determine gene expression using quantitative PCR, Platinum qPCR Supermix-UDG was used on the Strategene Mx3005p QPCR system. All gene expression data was determined based on standard curves for each gene using whole brain RNA and normalized to $\beta$-actin. The average ratio of the target gene and $\beta$-actin for the vehicle treatment was normalized to $100 \%$ and differences from the vehicle were calculated for each treatment.
Statistical Methods

Student's $t$ test was used for comparisons of neurochemical data and quantitative PCR data between the haloperidol and vehicle treatments. ANOVA with Fisher's PLSD post hoc tests were used to make comparisons across drug treatments and genotype for neurochemical data and quantitative PCR data. A $p$ value of less than 0.05 was used as the level of significance.

\section{Results}

Mechanisms Regulating NR4A Gene Expression

To investigate the regulation of the NR4A genes, Nurr1null heterozygous and wild-type mice were used. Based on the neurochemistry results, GBL produced a modest but not significant increase in tissue dopamine in the nucleus accumbens. Eticlopride, however, produced a modest reduction in tissue dopamine levels (Table 2). GBL treatment produced a significant twofold increase in Nur77 expression in the VTA, while eticlopride treatment had a more striking effect, producing a fourfold increase in Nur77 expression in the VTA. Each of these effects was similar across Nurr1 genotypes (Fig. 2). These data demonstrate that directionally, GBL and eticlopride had similar effects on Nur77 expression with eticlopride having a greater effect on inducing Nur77 expression. Nurr1 expression, however, was regulated differently as compared to Nur77. Measurement of Nurr1 expression in the VTA revealed a significant reduction in Nurr1 expression in both the $+/+$ and $+/-$ mice (Fig. 3). In fact, a greater reduction in Nurr1 was found in the heterozygous mice even though dopamine levels were less affected in these mice. One technical note is that these Lux primers for Nurr1 measure Nurr1 between exons 7 and 8 . Even though the Nurr1 gene is disrupted with a neomycin sequence in exon 3 , it is still fully transcribed through exons 7 and 8 . Interestingly, Nurr1

Table 1 Lux primers used for quantitative real-time PCR

\begin{tabular}{lll}
\hline Gene & Forward primer & Reverse primer \\
\hline$\beta$-actin & GGATCAGCAAGCAGGAGTACGA & CGGACAACGCAGCTCAGTAACAGTCG \\
Nur77 (NR4A1) & CGGGCTTGGGTGTTGATGTTCCG & TGTCGATCAGTGATGAGGACCA \\
Nurr1 (NR4A2) & ATTGCTGCCCTGGCTATGGT & GACCATCCCATTATTGAAAGTCACATGGTC \\
Nor1 (NR4A3) & CGCACGGATGGTTAAGGAAGTTGTGCG & GGCTCCTCTTGTAGTGGGCTCT \\
Dopamine transporter & CACATACCCCTGCTTCCTCCTGTATGTG & AGGATGTGGCGATGATCCAG \\
Tyrosine hydroxylase & GACATTGCCCAGAGATGCAAGTCCAATGTC & TGTTGGCTGACCGCACATTT \\
DOPA decarboxylase & CACCTTCCAGTAGGGCCACCAAGGTG & GGGAGGAGTGATCCAGGGAAGT \\
Dopamine D2 receptor & CACCTAAGTGAACAGGCGGAGAATGGATG & AGGATGTGGCGATGATCCAG \\
Vesicular monoamine transporter & CACCAGAGACAGCTCCTTTCCTGGTG & GGATGGCTGGAGCACAAAGAG \\
\hline
\end{tabular}


Table 2 Dopamine and DOPAC levels in $+/+$ and $+/-$ mice treated with GBL or eticlopride

\begin{tabular}{lll}
\hline Treatment & Dopamine & DOPAC \\
\hline$+/+$ Vehicle & $0.520 \pm 0.073$ & $0.122 \pm 0.003$ \\
$+/-$ Vehicle & $0.566 \pm 0.074$ & $0.145 \pm 0.023$ \\
$+/+\gamma$-Butyrolactone & $0.688 \pm 0.150$ & $0.106 \pm 0.005$ \\
$+/-\gamma$-Butyrolactone & $0.626 \pm 0.102$ & $0.133 \pm 0.009$ \\
$+/+$ Eticlopride & $0.449 \pm 0.066$ & $0.114 \pm 0.003$ \\
$+/-$ Eticlopride & $0.370 \pm 0.046$ & $0.114 \pm 0.007$ \\
\hline
\end{tabular}

All values in picograms per micrograms of protein

expression was differentially affected between the $+/+$ and $+/-$ mice as a result of eticlopride treatment. Eticlopride significantly increased Nurrl expression in $+/+$ mice but had no effect on Nurr1 expression in the $+/-$ mice (Fig. 3). However, eticlopride had a greater effect on tissue dopamine levels in the $+/-$ than the $+/+$ mice (Table 2 ).

Dopamine Neurotransmission Gene Expression After Induction of NR4A Genes

Male HSD:ICR outbred mice were used to investigate the relationship between induction of NR4A genes and the expression of dopamine neurotransmission genes in the VTA in combination with effects on dopamine neurochemistry in the nucleus accumbens. Based on neurochemical measurements, haloperidol treatment was effective at

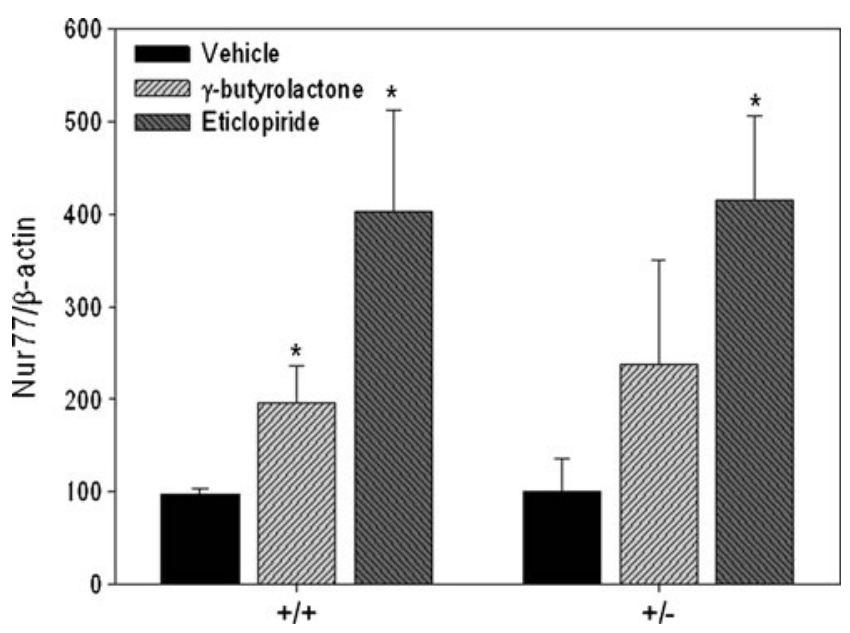

Fig. 2 Nur77 expression in the ventral tegmental area after either $\gamma$-butyrolactone or eticlopride in Nurr1 wild-type $(+/+)$ and heterozygous $(+/-)$ mice. Both $\gamma$-butyrolactone and eticlopride significantly increased Nur77 expression, with the exception of $\gamma$-butyrolactone in the $+/-$ mice. ${ }^{*} p<0.05$, significant difference from the vehicle treatment after ANOVA with post hoc comparison

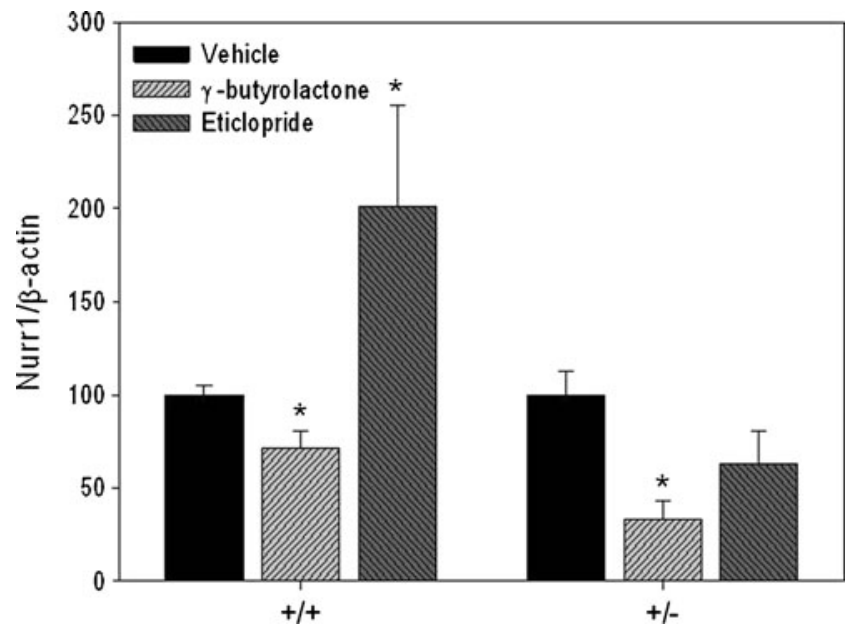

Fig. 3 Nurr1 expression in the ventral tegmental area after either $\gamma$-butyrolactone or eticlopride in Nurrl wild-type $(+/+)$ and heterozygous $(+/-)$ mice. While $\gamma$-butyrolactone significantly decreased Nurr1 expression in both $+/+$ and $+/-$ genotypes, eticlopride significantly increased Nurr1 expression only in the $+/+$ mice with no effect in the $+/-$ mice. ${ }^{*} p<0.05$, significant difference from the vehicle treatment after ANOVA with post hoc comparison

altering dopamine neurotransmission. Haloperidol resulted in a significant reduction in tissue dopamine levels at $1 \mathrm{~h}$ but produced a significant increase in tissue dopamine levels at $4 \mathrm{~h}$ (Table 3). The 1-h time point was chosen as sufficient time to induce gene expression with a D2 receptor antagonist (Maheux et al. 2005). The 4-h time point was chosen as sufficient time to determine how changes in transcription factor expression could affect the regulation of dopamine neurotransmission gene expression. Measurement of gene expression revealed that $1 \mathrm{~h}$ after haloperidol, Nur77 and Nor1 expression was significantly elevated. Haloperidol, however, had no effect on Nurr1 expression (Fig. 4). Dopamine neurotransmission genes were then measured in the VTA $4 \mathrm{~h}$ after haloperidol treatment. This analysis revealed a significant increase in TH and DAT mRNA expression. No significant changes in DOPA decarboxylase, dopamine D2 receptor, or vesicular monoamine transporter 2 were found (Fig. 5). Since both $\mathrm{TH}$ and DAT have been implicated as being regulated by Nurrl, these data suggest increased expression of other

Table 3 Dopamine and DOPAC levels after haloperidol treatment

\begin{tabular}{lcl}
\hline Treatment & Dopamine & DOPAC \\
\hline Vehicle, 1 h & $0.478 \pm 0.0785$ & $0.0941 \pm 0.0041$ \\
Haloperidol, 1 h & $0.109 \pm 0.0205^{*}$ & $0.0922 \pm 0.0177$ \\
Vehicle, 4 h & $0.5885 \pm 0.203$ & $0.1422 \pm 0.025$ \\
Haloperidol, 4 h & $1.434 \pm 0.284^{*}$ & $0.3208 \pm 0.0342^{*}$ \\
\hline
\end{tabular}

All values in picograms per microgram of protein ${ }^{*} p<0.05$ after ANOVA and post hoc comparison 


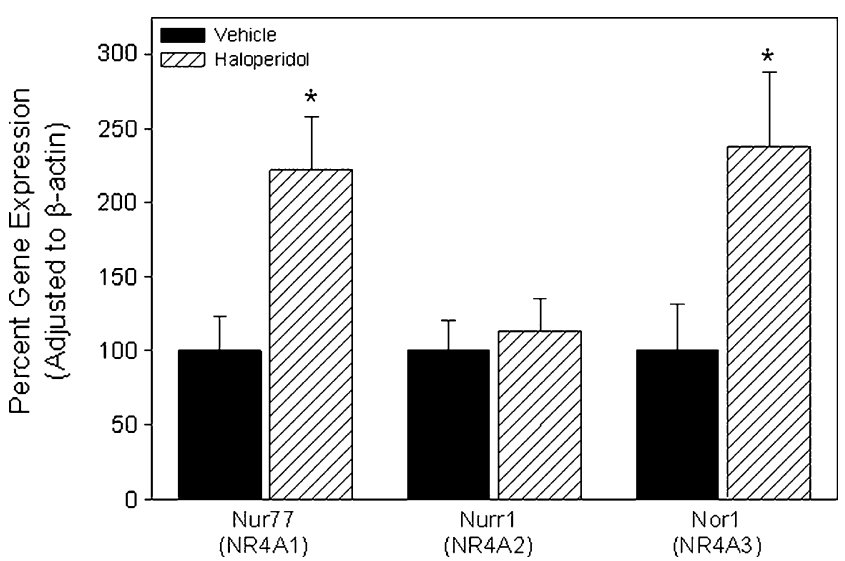

Fig. 4 Dopamine neuron gene expression in the ventral tegmental area $1 \mathrm{~h}$ after a $1-\mathrm{mg} / \mathrm{kg}$ systemic injection of haloperidol. Nur77 and Nor1 were significantly elevated after treatment, while no changes in Nurr1 expression were found. ${ }^{*} p<0.05$, significant difference from the vehicle treated after Student's $t$ test

NR4A genes (i.e., Nur77 and Nor1) could have an important role in regulation of dopamine neurotransmission genes that result from treatment with a D2 receptor antagonist.

\section{Discussion}

The current study investigated the regulation of NR4A gene expression in the VTA as well as subsequent effects on dopamine neurotransmission gene expression. The first aspect of these studies was to determine the mechanisms that regulate NR4A gene expression. Previous experiments have suggested that antagonism of the D2 receptor is the mechanism through which Nurrl expression is enhanced in dopamine neurons while stimulation of the $\mathrm{D} 2$ receptor can reduce Nurr1 expression. Evidence in support of antagonism of the D2 receptor increasing Nurr1 is first that Nurr1 levels are elevated in D2 receptor knockout mice and second, Nurr1 levels are increased after systemic treatment with D2 receptor antagonists (Tseng et al. 2000; Maheux et al. 2005). Furthermore, Bannon et al. reported reduced Nurr1 expression with cocaine use, a condition that decreases dopamine reuptake which could result in excessive autoreceptor stimulation (Bannon et al. 2002). By comparing GBL, which blocks impulse flow of dopamine neurons and subsequent dopamine release, with a systemic D2 receptor antagonist, which results in an increase in activity of dopamine neurons and an increase in dopamine release with reduced activation of the dopamine autoreceptor (reviewed in Tzschentke 2001), the effects of dopamine neuron activity could be differentiated from activation of the dopamine autoreceptor. The current data found that GBL significantly and rapidly (within $1 \mathrm{~h}$ ) reduced Nurr1 expression in the VTA. The D2 receptor antagonist eticlopride had only a modest effect on Nurr1 expression. This treatment, however, was sufficient to significantly induce Nur77 expression.

These data demonstrate several important observations about the regulation of Nurr1 and Nur77 expression. First, Nurr1 expression is regulated differently than that of Nur77. Specifically, impulse flow in the VTA dopamine neurons appears to be essential for maintaining Nurr1 expression with the capacity for a rapid downregulation in Nurr1 RNA levels with reduced dopamine neuron activity. This is demonstrated by the reduction in Nurr1 expression within $1 \mathrm{~h}$ after GBL treatment. The electrophysiology properties of VTA dopamine neurons mainly consist of spontaneously active neurons that change to burst firing in response to relevant environmental stimuli such as reward
Fig. 5 Dopamine neuron gene expression in the ventral tegmental area $4 \mathrm{~h}$ after a $1-\mathrm{mg} / \mathrm{kg}$ systemic injection of haloperidol. Tyrosine hydroxylase and dopamine transporter were significantly elevated after haloperidol treatment. Dopamine decarboxylase, dopamine D2 receptor, and vesicular monoamine transporter 2 were not significantly affected. $* p<0.05$, significant difference from the vehicle treated after Student's $t$ test

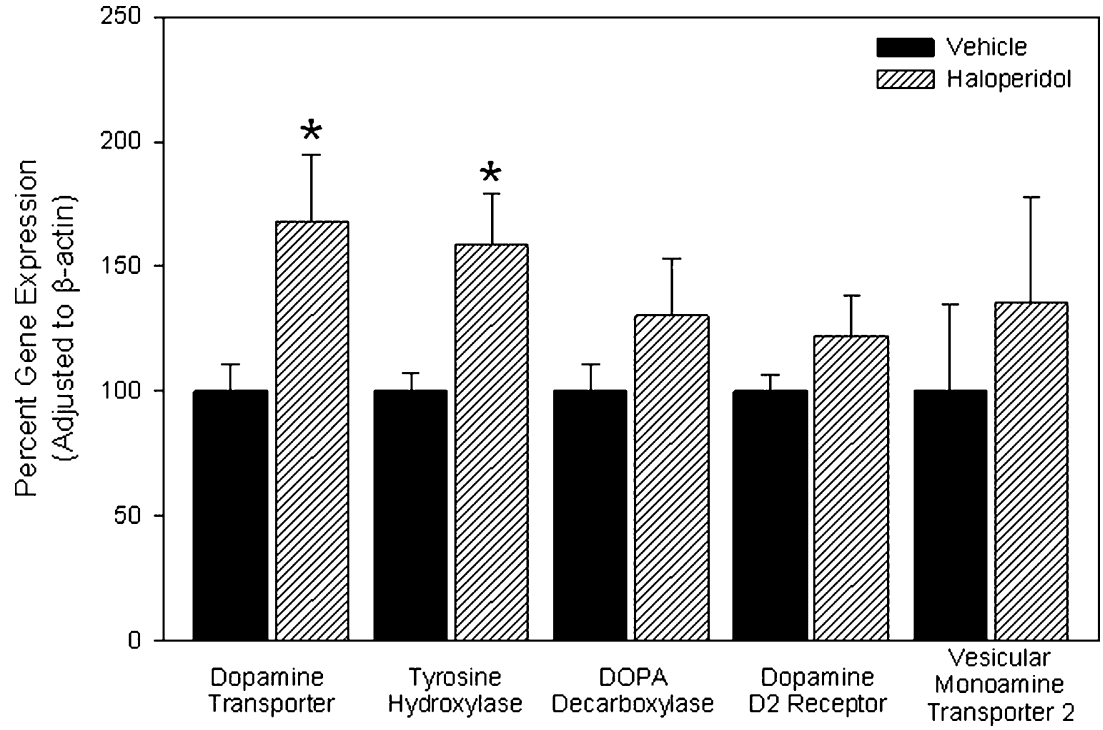


(Tzschentke 2001). Based on the current data, we propose that spontaneous and/or burst activity of VTA dopamine neurons is necessary for maintaining Nurrl expression. Also demonstrated by using the Nurrl $+/+$ and $+/-$ mice and eticlopride is that dopamine neuron function resulting from a deficit in Nurr1 has an impact on whether a D2 receptor antagonist can induce Nurr1 expression. These data suggest that a D2 receptor antagonist is not necessarily sufficient to increase Nurr1 expression and that the level of Nurr1 function can impact the responsiveness of these neurons to D2 receptor antagonists. The Nurr1 +/genotype has been shown to increase basal extracellular dopamine levels in the shell of the nucleus accumbens (Moore et al. 2008). This change could alter the responsiveness of both post-synaptic dopamine receptors and the dopamine autoreceptors and change the way the +/- VTA dopamine neurons respond to a D2 receptor antagonist.

In dopamine neurons in the VTA, Nurrl is expressed at relatively high levels. Basal Nur77 expression, however, is low, allowing for a large capacity for a rapid, relative increase in expression. Previous data has implicated increases in neuronal activity, such as after a seizure, as a mediator to induce Nur77 expression (Watson and Milbrandt 1989, 1990). In VTA dopamine neurons, the expression of Nur77 appears to be regulated by a combination of impulse flow as well as reduced activation of the dopamine autoreceptors. GBL treatment caused a modest twofold increase in Nur77 expression while eticlopride caused a fourfold increased Nur77 expression. Based on this data, we propose that the combination of reduced activation of the D2 autoreceptor that results from GBL treatment and an increase in dopamine neuron firing rate and dopamine release that results from eticlopride treatment combine to contribute to the increase in Nur77 expression.

The second experiment was conducted to determine if induction of Nur77 and/or Nor1 could have functional consequences on the regulation of dopamine neurotransmission genes. Both Nur77 and Nor1 were induced after $1 \mathrm{~h}$ of treatment with haloperidol while Nurr1 was not. To determine if this could have effects on dopamine neurotransmission, samples were taken $4 \mathrm{~h}$ after haloperidol treatment and dopamine neurotransmission gene expression was measured in the VTA. Our results found an increase in TH and DAT expression at $4 \mathrm{~h}$ after haloperidol treatment. As the NR4A transcription factors all possess similar abilities to bind to response elements in promoter regions of target genes, any increases in Nur77 or Norl levels could function similarly to Nurr1 and therefore, affect the expression of the same genes that are controlled by Nurr1 and regulate dopamine neurotransmission genes and dopamine neurotransmission.

Previous research has demonstrated that $\mathrm{TH}$ gene expression can be directly regulated by Nurr1 (Sakurada et al. 1999; Cazorla et al. 2000). The TH promoter region contains known sequences of NBRE that are necessary for Nurr1 regulation of reporter gene expression (Kim et al. 2003). Additionally, Nurr1 can induce TH gene expression in embryonic stem cells. The role of Nurrl in the regulation of the DAT is not as straightforward. No difference in DAT expression was found in the VTA of the Nurr1 +/- mice (Eells et al. 2006). However, Bannon et al. suggested a role for Nurr1 in DAT regulation as cocaine users who have Nurrl deficiencies due to chronic use of the drug also had reduced DAT expression (Bannon et al. 2002). The transcriptional activity of human DAT has been shown to be enhanced by Nurr1 (Sacchetti et al. 1999; Sacchetti et al. 2001). Nurr1 regulation of the DAT promoter was found to be independent of the NBRE and the mechanism through which Nurr1 could regulate transcription from this promoter is currently unclear (Sacchetti et al. 2001). This research also demonstrated that both Nurr1 and Nur77 could increase reporter gene expression from the DAT promoter in SN4741 dopamine cell lines, although Nurrl effects were greater than that of Nur77 (Sacchetti et al. 2001). Nor1, however, had no significant effect on the DAT promoter in this study (Sacchetti et al. 2001). Although the expression of Nur77 and Nor1 relative to TH and DAT are only correlative, these data still provide evidence that induction of Nur77 and Nor1 could be involved in the regulation of dopamine neurotransmission genes and could have a role in how dopamine neurons are affected by antipsychotics. Further data is needed to directly confirm the role of induction of Nur77 and/or Nor1 in the regulation of these dopamine neurotransmission genes, such as in knockout mice or using RNA interference to block expression. Also of interest is whether the NR4A genes are regulated in dopamine neurons under physiological conditions and not just the result of pharmacological manipulation.

The dopamine D2 receptor, which serves as the primary autoreceptor, is negatively coupled to cAMP levels and protein kinase A. Blocking the D2 receptor increases dopamine synthesis via phosphorylation of TH. Changes in dopamine release can, therefore, alter phosphorylation of $\mathrm{TH}$ and alter dopamine synthesis. Based on the observations that Nurrl is implicating in regulating $\mathrm{TH}$, that dopamine synthesis is impaired in Nurr1 +/- mice, and that Nur77, Nurr1, and Nor1 mRNA expression is dynamically regulated, we propose that NR4A levels function as a longer feedback loop between dopamine neuron activity and subsequent regulation of gene expression. Based on this hypothesis, reduced activity of dopamine neuron which results in reduced Nurr1 expression, will produce a reduction in dopamine neurotransmission genes such as TH. Additionally, increased neuron activity could enhance Nurr1, or the functionally similar genes Nur77 and/or Nor1 to increase expression of TH. Just as there is considerable feedback from the dopamine 
autoreceptor to regulate dopamine synthesis, release, and reuptake, this hypothesizes a similar feedback mechanism that is mediated by altering gene and protein expression as compared to the relatively rapid autoreceptor feedback mediated primarily via phosphorylation.

\section{Conclusions}

These data suggest that the maintenance of Nurr1 expression requires impulse flow in VTA dopamine neurons while the combination of reduced D2 receptor activation coupled with dopamine neuron activity and/or dopamine release, appears to be the mechanism for increasing Nur77 expression. Since the NR4A genes have been linked with the regulation of dopamine neurotransmission, the current data demonstrate that elevation of Nur77 and Nor1 expression in the VTA correspond to subsequent elevation of the dopamine neurotransmission genes $\mathrm{TH}$ and the DAT. This suggests that induction of Nur77 and/or Nor1 could also have important implications in the regulation of dopamine neurotransmission. Therefore, the regulation of NR4A genes could be a very important mechanism in regulating dopamine neurotransmission and expression of dopamine neurotransmission genes.

Acknowledgements This study was supported by the National Institute for Neurological Disorders (R21NS058375)and Stroke and the National Institute for Mental Health (R15MH084209).

Open Access This article is distributed under the terms of the Creative Commons Attribution Noncommercial License which permits any noncommercial use, distribution, and reproduction in any medium, provided the original author(s) and source are credited.

\section{References}

Bannon MJ, Pruetz B, Manning-Bog AB, Whitty CJ, Michelhaugh SK, Sacchetti P, Granneman JG, Mash DC, Schmidt CJ (2002) Decreased expression of the transcription factor NURR1 in dopamine neurons of cocaine abusers. Proc Natl Acad Sci U S A 99(9):6382-6385

Castillo SO, Baffi JS, Palkovits M, Goldstein DS, Kopin IJ, Witta J, Magnuson MA, Nikodem VM (1998) Dopamine biosynthesis is selectively abolished in substantia nigra/ventral tegmental area but not in hypothalamic neurons in mice with targeted disruption of the Nurr1 gene. Mol Cell Neurosci 11(1-2):36-46

Cazorla P, Smidt MP, O'Malley KL, Burbach JP (2000) A response element for the homeodomain transcription factor Ptx3 in the tyrosine hydroxylase gene promoter. J Neurochem 74(5):1829 1837

Eells JB, Brown T (2009) Repeated developmental exposure to chlorpyrifos and methyl parathion causes persistent alterations in nicotinic acetylcholine subunit mRNA expression with chlorpyrifos altering dopamine metabolite levels. Neurotoxicol Teratol 31(2):98-103

Eells JB, Rives JE, Yeung SK, Nikodem VM (2001) In vitro regulated expression of tyrosine hydroxylase in ventral midbrain neurons from Nurr1-null mouse pups. J Neurosci Res 64(4):322-330
Eells JB, Lipska BK, Yeung SK, Misler JA, Nikodem VM (2002) Nurr1-null heterozygous mice have reduced mesolimbic and mesocortical dopamine levels and increased stress-induced locomotor activity. Behav Brain Res 136(1):267-275

Eells JB, Misler JA, Nikodem VM (2006) Reduced tyrosine hydroxylase and GTP cyclohydrolase mRNA expression, tyrosine hydroxylase activity, and associated neurochemical alterations in Nurr1-null heterozygous mice. Brain Res Bull 70 (2): $186-195$

Gil M, McKinney C, Lee M, Eells JB, Phyillaier MA, Nikodem VM (2007) Regulation of GTP cyclohydrolase I expression by orphan receptor Nurr1 in cell culture and in vivo. J Neurochem 101:142150

Gilbert F, Morissette M, St-Hilaire M, Paquet B, Rouillard C, Di Paolo T, Levesque D (2006) Nur77 gene knockout alters dopamine neuron biochemical activity and dopamine turnover. Biol Psychiatry 60(6):538-47

Hermanson E, Joseph B, Castro D, Lindqvist E, Aarnisalo P, Wallen A, Benoit G, Hengerer B, Olson L, Perlmann T (2003) Nurr1 regulates dopamine synthesis and storage in MN9D dopamine cells. Exp Cell Res 288(2):324-334

Honkaniemi J, Sharp FR (1999) Prolonged expression of zinc finger immediate-early gene mRNAs and decreased protein synthesis following kainic acid induced seizures. Eur J Neurosci 11(1):10-17

Hosford DA, Simonato M, Cao Z, Garcia-Cairasco N, Silver JM, Butler L, Shin C, McNamara JO (1995) Differences in the anatomic distribution of immediate-early gene expression in amygdala and angular bundle kindling development. J Neurosci 15(3 Pt 2):2513-2523

Iwawaki T, Kohno K, Kobayashi K (2000) Identification of a potential nurrl response element that activates the tyrosine hydroxylase gene promoter in cultured cells. Biochem Biophys Res Commun 274(3):590-595

Jankovic J, Chen S, Le WD (2005) The role of Nurr1 in the development of dopaminergic neurons and Parkinson's disease. Prog Neurobiol 77(1-2):128-138

Kadkhodaei B, Ito T, Joodmardi E, Mattsson B, Rouillard C, Carta M, Muramatsu S, Sumi-Ichinose C, Nomura T, Metzger D, Chambon P, Lindqvist E, Larsson NG, Olson L, Bjorklund A, Ichinose H, Perlmann T (2009) Nurrl is required for maintenance of maturing and adult midbrain dopamine neurons. J Neurosci 29(50):1592315932

Kim KS, Kim CH, Hwang DY, Seo H, Chung S, Hong SJ, Lim JK, Anderson T, Isacson O (2003) Orphan nuclear receptor Nurr1 directly transactivates the promoter activity of the tyrosine hydroxylase gene in a cell-specific manner. J Neurochem 85 (3):622-634

Maheux J, Ethier I, Rouillard C, Levesque D (2005) Induction patterns of transcription factors of the nur family (nurr1, nur77, and nor-1) by typical and atypical antipsychotics in the mouse brain: implication for their mechanism of action. J Pharmacol Exp Ther 313(1):460-473

Maira M, Martens C, Philips A, Drouin J (1999) Heterodimerization between members of the Nur subfamily of orphan nuclear receptors as a novel mechanism for gene activation. Mol Cell Biol 19(11):7549-7557

Maira M, Martens C, Batsche E, Gauthier Y, Drouin J (2003) Dimerspecific potentiation of NGFI-B (Nur77) transcriptional activity by the protein kinase A pathway and AF-1-dependent coactivator recruitment. Mol Cell Biol 23(3):763-776

Moore TM, Brown T, Cade M, Eells JB (2008) Alterations in amphetamine-stimulated dopamine overflow due to the Nurr1null heterozygous genotype and postweaning isolation. Synapse 62(10):764-774

Murphy EP, Dobson AD, Keller C, Conneely OM (1996) Differential regulation of transcription by the NURR1/ 
NUR77 subfamily of nuclear transcription factors. Gene Expr 5(3):169-179

Paulsen RF, Granas K, Johnsen H, Rolseth V, Sterri S (1995) Three related brain nuclear receptors, NGFI-B, Nurr1, and NOR-1, as transcriptional activators. J Mol Neurosci 6(4):249-255

Perlmann T, Jansson L (1995) A novel pathway for vitamin A signaling mediated by RXR heterodimerization with NGFI-B and NURR1. Genes Dev 9(7):769-782

Philips A, Maira M, Mullick A, Chamberland M, Lesage S, Hugo P, Drouin J (1997) Antagonism between Nur77 and glucocorticoid receptor for control of transcription. Mol Cell Biol 17(10):5952-5959

Sacchetti P, Brownschidle LA, Granneman JG, Bannon MJ (1999) Characterization of the 5'-flanking region of the human dopamine transporter gene. Brain Res Mol Brain Res 74(1-2):167-174

Sacchetti P, Mitchell TR, Granneman JG, Bannon MJ (2001) Nurr1 enhances transcription of the human dopamine transporter gene through a novel mechanism. J Neurochem 76 (5): $1565-1572$

Sakurada K, Ohshima-Sakurada M, Palmer TD, Gage FH (1999) Nurr1, an orphan nuclear receptor, is a transcriptional activator of endogenous tyrosine hydroxylase in neural progenitor cells derived from the adult brain. Development 126(18):4017-4026

Saucedo-Cardenas O, Conneely OM (1996) Comparative distribution of NURR1 and NUR77 nuclear receptors in the mouse central nervous system. J Mol Neurosci 7(1):51-63

Saucedo-Cardenas O, Quintana-Hau JD, Le WD, Smidt MP, Cox JJ, De Mayo F, Burbach JP, Conneely OM (1998) Nurr1 is essential for the induction of the dopaminergic phenotype and the survival of ventral mesencephalic late dopaminergic precursor neurons. Proc Natl Acad Sci U S A 95(7):4013-4018

Tseng KY, Roubert C, Do L, Rubinstein M, Kelly MA, Grandy DK, Low MJ, Gershanik OS, Murer MG, Giros B, Raisman-Vozari R (2000) Selective increase of Nurr1 mRNA expression in mesencephalic dopaminergic neurons of D2 dopamine receptordeficient mice. Brain Res Mol Brain Res 80(1):1-6

Tzschentke TM (2001) Pharmacology and behavioral pharmacology of the mesocortical dopamine system. Prog Neurobiol 63(3):241320

Watson MA, Milbrandt J (1989) The NGFI-B gene, a transcriptionally inducible member of the steroid receptor gene superfamily: genomic structure and expression in rat brain after seizure induction. Mol Cell Biol 9(10):4213-4219

Watson MA, Milbrandt J (1990) Expression of the nerve growth factor-regulated NGFI-A and NGFI-B genes in the developing rat. Development 110(1):173-183

Wilson TE, Fahrner TJ, Johnston M, Milbrandt J (1991) Identification of the DNA binding site for NGFI-B by genetic selection in yeast. Science 252(5010):1296-1300

Wu Q, Li Y, Liu R, Agadir A, Lee MO, Liu Y, Zhang X (1997) Modulation of retinoic acid sensitivity in lung cancer cells through dynamic balance of orphan receptors nur77 and COUP-TF and their heterodimerization. EMBO J 16(7):1656-1669

Xing G, Zhang L, Heynen T, Li XL, Smith MA, Weiss SR, Feldman AN, Detera-Wadleigh S, Chuang DM, Post RM (1997) Rat nurr1 is prominently expressed in perirhinal cortex, and differentially induced in the hippocampal dentate gyrus by electroconvulsive vs. kindled seizures. Brain Res Mol Brain Res 47(1-2):251-261

Zetterström RH, Williams R, Perlmann T, Olson L (1996) Cellular expression of the immediate early transcription factors Nurr1 and NGFI-B suggests a gene regulatory role in several brain regions including the nigrostriatal dopamine system. Brain Res Mol Brain Res 41(1-2):111-120

Zetterström RH, Solomin L, Jansson L, Hoffer BJ, Olson L, Perlmann $\mathrm{T}$ (1997) Dopamine neuron agenesis in Nurr1-deficient mice. Science 276(5310):248-250 